\title{
POTENCIAL FORRAGEIRO DE SEIS HÍBRIDOS DE SORGO COM CAPIM SUDÃO
}

\author{
MÁRCIO HENRIQUE RIBEIRO GONTIJO ${ }^{1}$, ANA LUIZA COSTA CRUZ BORGES ${ }^{2}$, LÚCIO \\ CARLOS GONÇALVES ${ }^{2}$, JOSÉ AVELINO SANTOS RODRIGUES ${ }^{3}$, SILAS PRIMOLA GOMES ${ }^{4}$, \\ IRAN BORGES'2; NORBERTO MÁRIO RODRIGUEZ ${ }^{2}$ e MARIANA MAGALHÃES CAMPOS ${ }^{4}$ \\ ${ }^{I}$ Mestre em Zootecnia pela Escola de Veterinária da UFMG, Caixa postal 567, CEP: 30123-970 - Belo Horizontel \\ $M G$ \\ ${ }^{2}$ Professor(a) da Escola de Veterinária da UFMG, Caixa postal 567, CEP: 30123-970, Belo Horizonte/MG \\ ${ }^{3}$ Pesquisador da Embrapa Milho e Sorgo, Sete Lagoas/MG \\ ${ }^{4}$ Doutorando(a) em Zootecnia pela Escola de Veterináriada UFMG; silaspg@ig.com.br, marimcampos@gmail.com
}

Revista Brasileira de Milho e Sorgo, v.7, n.1, p. 33-43, 2008

\begin{abstract}
RESUMO - Avaliaram-se quatro híbridos experimentais e duas cultivares comerciais de Sorghum bicolor cv bicolor x Sorghum bicolor cv sudanense quanto às características agronômicas: produções de matéria verde por hectare (MV/ha), matéria seca (MS/ha), altura das plantas, número de plantas/ha, taxa de rebrota e relação folha/haste. Os plantios ocorreram na transição do período seco para o período chuvoso. Os híbridos foram submetidos a três cortes sucessivos, realizados em duas épocas de plantio. Foi empregado um delineamento experimental de blocos ao acaso e a comparação de médias foi efetuada pelo teste de SNK, a 5\% de probabilidade. Os híbridos estudados não diferiram para a maioria das características avaliadas, com exceção da população de plantas, em que o híbrido experimental ATF 54 x CMSXS 912, com 848 mil plantas/ há, foi semelhante $(\mathrm{P}>0,05)$ aos híbridos testemunhas (comerciais) AG2501C, com 780 mil plantas/ha, e ao BRS800, com 749 mil plantas/ha, sendo superior $(\mathrm{P}<0,05)$ aos demais híbridos. Os resultados de produtividade indicam o potencial dos híbridos de sorgo com capim Sudão estudados para serem utilizados como alternativa para a produção de forragem em regime de corte, na transição do período seco para o período chuvoso.
\end{abstract}

Palavras-chave: Características agronômicas, híbridos de sorgo com capim Sudão.

\section{FORAGE POTENTIAL OF SIX SORGHUM-SUDANGRASS HYBRIDS}

ABSTRACT - Four experimental hybrids and two commercial Sorghum bicolor $c v$ bicolor $x$ Sorghum bicolor $c v$ sudanense hybrids were evaluated regarding the following agronomical characteristics: green matter production per hectare, dry matter production, plant height, plant number per hectare, regrowth rate and leaf/stem ratio. Plantings occurred in the dry-rainy transition period. The hybrids were submitted to three successive cuts and two planting periods. A randomized blocks experimental design was used and the means were compared by the SNK test $(\mathrm{P}<0.05)$. The studied hybrids did not show statistical difference for the majority of the evaluated characteristics, except the experimental hybrid ATF54 x CMSX5912, with 847.000 
plants/ha, being similar ( $\mathrm{P}>0.05$ ) to the commercial hybrids AG2501C (control), with 780.000 plants/ha, and to BRS800, with 749.000 plants/ha, and superior to the other hybrids. The productivity results indicated the potential of utilization of the studied sorghum-Sudan grass hybrids as an alternative for the cut forage production, in the transition period from dry to rainy season.

Keywords: Agronomic characteristics, Sorghum-sudangrass hybrid.

Há na região central do Brasil, a partir de março ou abril, as pastagens diminuem sua produção de massa e se tornam menos nutritivas, comprometendo o desenvolvimento do rebanho. O uso de forragem cultivada é geralmente indicada como alternativa para reduzir o efeito dos períodos de carência alimentar dos animais em pastejo (Tomich et al., 2003). O produtor deve buscar alternativas para suprir a baixa disponibilidade de forragem, o que dificulta a viabilidade econômica da atividade pecuária e impede que o potencial de produção das plantas forrageiras seja aproveitado ao longo de todo o ano (Aguiar et al., 2006). Algumas experiências têm demonstrado que é possível manter o nível de produtividade quando se utilizam forrageiras como alternativa para pastejo ou corte verde, complementando o pasto perene.

O sorgo é uma planta que pode ser comparada ao milho, em relação ao seu valor agronômico e nutritivo. No entanto, em termos de exigências e produção, o sorgo aparece como uma alternativa interessante, uma vez que é mais adaptado à seca, dada a sua capacidade de recuperar-se e produzir grãos após um período de estiagem, produzindo mais matéria seca em áreas de solo menos fértil, quando comparado ao milho (Rodrigues et al., 2002).

Por sua facilidade de cultivo, resistência à seca, rapidez de estabelecimento e crescimento e, principalmente, por sua facilidade de manejo para corte ou pastejo direto, além do bom valor nutritivo e da alta produção de forragem, os sorgos para corte e/ou pastejo têm sido muito bem aceitos pelos pecuaristas. Apesar do alto potencial produtivo da cultura de sorgo e da grande disponibilidade de cultivares com características que possibilitam a adequação desses materiais às diferentes regiões, observa-se, muitas vezes, produção baixa e irregular (Gontijo Neto et al., 2002). $\mathrm{Na}$ região Central do Brasil, os híbridos de sorgo com capim Sudão têm se adaptado bem a algumas situações de cultivo, como plantio em sucessão ou após uma cultura precoce de verão (Rodrigues, 2000).

É possível, nessa situação, conseguir até três cortes ou pastejos nos meses que antecedem o inverno, possibilitando, assim, um equilíbrio na produtividade do rebanho e uma melhor exploração da propriedade. Zago (1997) sugeriu outra alternativa, como o plantio do sorgo de corte e/ou pastejo no final do inverno, nos meses de agosto e setembro, para suprir a falta de forragem que comumente ocorre na entrada do verão, quando já se esgotaram as reservas da seca e as pastagens de verão não se apresentam ainda com desenvolvimento satisfatório.

O sorgo forrageiro para corte e/ou pastejo é proveniente de cruzamentos de espécies do gênero Sorghum. Usa-se como macho uma linhagem de capim Sudão 
(Sorghum bicolor cv sudanense) e como fêmea uma linhagem de sorgo granífero (Sorghum bicolor cv bicolor). O híbrido resultante desse cruzamento é uma planta de crescimento vegetativo rápido, abundante perfilhamento e fácil estabelecimento. Possui boa resistência à privação hídrica, apresentando grande rusticidade e pouca exigência quanto à qualidade de solo, além de facilidade de manejo para corte ou pastejo direto, bom valor nutritivo e alta produção de forragem (Rodrigues, 2000).

O recente desenvolvimento de híbridos de sorgo com capim Sudão com boas produções quando comparados a milho para silagem, tem feito desse volumoso uma forrrageira alternativa para área de solos arenosos e com curtos períodos de estação chuvosa (Beyaert e Roy, 2005).

O híbrido de sorgo com capim Sudão pode ser uma boa opção de forragem com alta produtividade por área e adequado valor nutricional para alimentação de ruminantes, principalmente em sistemas de produção onde a oferta de alimentos volumosos de boa qualidade é sazonal, tornando a produção animal instável, ao longo do ano. Tomich et al. (2006) destacaram o alto teor protéico e a alta digestibilidade dessa forrageira, sendo uma opção de volumoso de elevado valor nutritivo para o período de escassez das pastagens.

Nesse contexto, objetivou-se determinar a produtividade, na época de transição do período seco para o período chuvoso, de quatro híbridos experimentais e dois híbridos comerciais de Sorghum bicolor cv sudanense $x$ Sorghum bicolor cv bicolor, em três cortes, através da avaliação das produções de MV/ ha, MS/ha, altura das plantas, número de plantas/ha, taxa de rebrota e relação folha/ haste.

\section{Material e Métodos}

Quatro híbridos experimentais e dois híbridos comerciais (testemunhas) de Sorghum bicolor $c v$ bicolor $x$ Sorghum bicolor $c v$ sudanense foram plantados nas dependências da Embrapa Milho e Sorgo, situada no Km 45 da MG 424, no município de Sete Lagoas - MG, entre as seguintes coordenadas: 190 de latitude sul e 440 de longitude oeste de Greenwich, com altitude média de $732 \mathrm{~m}$ e precipitação pluviométrica média de $1.340 \mathrm{~mm}$, da qual $86,2 \%$ ocorrem no período chuvoso de novembro a abril. Segundo a classificação de Köppen, clima do tipo AW (clima de savana, com inverno seco e temperatura média acima de $18^{\circ} \mathrm{C}$ no mês mais frio).

$\mathrm{O}$ plantio dos híbridos comerciais AG2501C e BRS800 e dos híbridos experimentais (ATF 54 x CMSXS 912, CMSXS 156 x CMSXS 912, CMSXS 157 x CMSXS 912 e CMSXS 210 x CMSXS 912) foi realizado em canteiros irrigados, com $5 \mathrm{~m}$ de comprimento, e 2,7m de largura, contendo quatro linhas, com espaçamento de $0,35 \mathrm{~m}$. Foram utilizadas quatro repetições por híbrido, em duas datas de plantio diferentes. No planejamento da metodologia experimental do presente trabalho, objetivouse uma padronização do intervalo entre cortes para ambas as épocas de plantio. Entretanto, devido a fatores ambientais, não foi possível manter essa padronização durante a execução do experimento. Para facilitar a descrição, os híbridos foram designados pelos números 1,2 , $3,4,5$ e 6 , respectivamente.

O primeiro plantio foi efetuado no dia 22 de agosto e o segundo, treze dias após o primeiro, no dia quatro de setembro.

Foram feitas adubações no plantio com $300 \mathrm{~kg}$ por hectare da fórmula 04-14-08 (N:P: $\mathrm{K}$ ) e de cobertura, após cada corte, com 100kg 
de uréia por hectare. Foram realizados três cortes sucessivos para cada época de plantio. $\mathrm{Na}$ primeira época, o primeiro corte ocorreu no dia 11 de outubro (cinqüenta dias após o plantio), o segundo no dia seis de novembro e o terceiro no dia três de dezembro, aos 26 (vinte e seis) e aos 27 (vinte e sete) dias de rebrota, respectivamente. $\mathrm{Na}$ segunda época de plantio, o primeiro corte ocorreu no dia 22 de outubro (quarenta e oito dias após o plantio), o segundo no dia 23 de novembro e o terceiro, no dia três de janeiro, aos 32 (trinta e dois) e 41 (quarenta e um) dias de rebrota, respectivamente.

Antes de cada corte, nas duas linhas centrais de cada canteiro, procedeu-se à contagem do número de plantas, sendo os resultados utilizados na determinação do número de plantas por hectare e da taxa de rebrota. As taxas de rebrota foram calculadas pela divisão do número total de plantas no momento do corte pelo número total de plantas calculadas no corte anterior. Também foi medida a altura das plantas pelo dimensionamento do espaço entre o nível do solo e a altura do horizonte visual das folhas.

Realizou-se o corte manual das plantas a cerca de $20 \mathrm{~cm}$ do solo, visando uma simulação de pastejo. Após os cortes, todo material colhido foi pesado em balança de campo tipo dinamômetro e utilizado para a determinação da produção de MV/ha e de MS/ha. Em cada corte, dez plantas de cada canteiro foram coletadas e tiveram suas partes separadas para determinação da relação folha/haste, que foi determinada na MV. O restante do material colhido foi picado, acondicionado em sacos de plástico, identificado e enviado para o laboratório de Nutrição Animal da Escola de Veterinária da UFMG.
As amostras foram pré-secadas em estufa de ventilação forçada, a $650 \mathrm{o}$, por 72 horas e moídas em moinho estacionário, com peneira de $1 \mathrm{~mm}$. Nas amostras pré-secadas, foram determinados os teores de $\mathrm{MS}$ a $105^{\circ} \mathrm{C}$, segundo a Cuniff (1995).

$\mathrm{O}$ delineamento experimental empregado foi o de blocos ao acaso, sendo quatro repetições e três cortes sucessivos em oito blocos (quatro repetições em cada um dos dois períodos). Os dados foram avaliados por meio de análise de variância e teste de média, utilizando-se o Sistema de Análises Estatísticas e Genéticas - SAEG (UNIVERSIDADE..., 2000). Para a comparação das médias, foi empregado o teste SNK (Student-Newman-Keuls), a 5\% de probabilidade. Também foram estimados os coeficientes de correlação entre as variáveis, através do coeficiente de correlação de Pearson.

O modelo estatístico utilizado para análise dos dados foi:

$$
\mathrm{y}_{\mathrm{ij}}=\alpha+\tau_{\mathrm{i}}+\beta_{\mathrm{j}}+\mathrm{e}_{\mathrm{ij}}
$$

Sendo que:

$\mathrm{y}_{\mathrm{ij}}=$ observação dos híbridos; $\alpha=$ constante geral; $\tau=$ cortes; $\beta=$ blocos; $\mathrm{e}=$ desvio aleatório associado a cada observação yij.

\section{Resultados e Discussão}

Na Tabela 1, verifica-se a produção de MV dos híbridos estudados, nos três cortes sucessivos.

Observando-se as médias dos híbridos, não houve diferença $(\mathrm{P}>0,05)$ entre os mesmos para a produção média de $\mathrm{MV} / \mathrm{ha}$, com valores absolutos variando entre 13,53 e 18,37 t/ha. Não houve diferença entre híbridos dentro de cada corte, sendo que a produção média de $\mathrm{MV} / \mathrm{ha}$ foi superior no segundo corte. $\mathrm{O}$ 
TABELA 1. Produção de matéria verde (MV), expressa em toneladas por hectare (t/ha), dos seis híbridos, nos três cortes realizados

\begin{tabular}{llllll}
\hline Híbridos & Corte $\mathbf{1}$ & Corte $\mathbf{2}$ & Corte 3 & Médias & Total \\
\hline 1 & 13,04 & 20,59 & 17,39 & 17,01 & 68,03 \\
2 & 12,01 & 14,75 & 13,82 & 13,53 & 54,11 \\
3 & 14,64 & 21,23 & 19,24 & 18,37 & 73,48 \\
4 & 11,01 & 20,91 & 12,72 & 14,88 & 59,52 \\
5 & 7,62 & 23,73 & 12,11 & 14,49 & 57,95 \\
6 & 9,33 & 19,74 & 11,83 & 13,63 & 54,53 \\
\hline Médias & $11,28 \mathrm{~b}$ & $20,16 \mathrm{a}$ & $14,52 \mathrm{~b}$ & 15,32 & \\
\hline
\end{tabular}

Teste SNK ( $<<0,05), C V=54,28 \%$. Letras minúsculas comparam médias na mesma. Híbridos: $1=$ AG2501C; $2=$ BRS800; 3 = ATF54 x 912; 4 = CMSXS 156 x CMSXS 912; $5=$ CMSXS 157 x CMSXS 912; $6=$ CMSXS 210 x CMSXS 912.

primeiro e o terceiro cortes tiveram produções médias de MV/ha, demonstrando a estabilidade de produção de forragem em três cortes consecutivos.

Tomich (2003) encontrou produções médias de MV/ha por corte variando de 19,4 a 25,1 t/ha, para doze híbridos de sorgo de corte e/ ou pastejo. Porém, o autor trabalhou no período de verão, o que dificulta a comparação com os resultados obtidos no presente experimento.

As produções totais de MV, que variaram de 54,11 a 73,48 t/ha, encontradas neste experimento, podem ser consideradas adequadas, principalmente devido ao fato de os plantios terem ocorrido no período de transição inverno/verão. Considerando que este estudo foi conduzido com plantas $\mathrm{C} 4$, limitações climáticas podem levar a uma menor atividade fotossintética, levando a uma menor produção de matéria verde, quando comparado a plantios feitos no verão (Wheeler, 1980).

As produções de MV/ha observadas neste estudo reafirmam a possibilidade de utilização estratégica de híbridos de sorgo com capim Sudão no período final de inverno, onde as pastagens, no Brasil Central, ainda estão se recuperando do período de estiagem. Zago (1997) relatou produções de MV de 40 a 60 t/ha para híbridos de sorgo com capim Sudão, em três cortes consecutivos, no Brasil Central. No presente estudo, foram encontrados dados semelhantes, sendo a produção média de MV dos seis híbridos estudados, em três cortes consecutivos, de 45,96 t/ha. Tomich et al. (2004), avaliando 25 genótipos de híbridos de sorgo e capim Sudão, observaram produção média variando de 24,4 a 37,8 t/ha. Segundo Rodrigues (2000), a produtividade de matéria verde obtida com diferentes híbridos de sorgo com capim Sudão, avaliados sob diversas condições do Brasil, mostra a ampla capacidade de adaptação dessa forrageira às condições tropicais e subtropicais do país.

Segundo Tomich et al. (2004), existem diversos fatores capazes de influenciar a produtividade de híbridos de sorgo com capim Sudão, como variabilidade genética, fertilidade do solo, disponibilidade de água, época de plantio, estádio de desenvolvimento da planta, cortes sucessivos e números de plantas por 
unidade de área. Contudo, existem poucas informações sobre os efeitos desses fatores sobre a qualidade da forragem produzida (Neumann et al., 2002b). No presente estudo, foram avaliados três cortes sucessivos, sendo esse fator responsável pela alteração na produtividade dos híbridos estudados. A produção média de MV/ha, no segundo corte, foi superior ao primeiro e terceiro cortes.

De maneira geral, as produções de MS/ha (Tabela 2) apresentaram um padrão próximo ao encontrado para as produções de MV/ha, porém, a produção de MS/ha, no terceiro corte, foi superior à encontrada no primeiro corte, sendo notada uma correlação de 0,97 $(\mathrm{P}<0,0001)$ entre esses dois parâmetros.

Não houve diferenças $(\mathrm{P}>0,05)$ entre as médias de produção de MS/ha dos híbridos, sendo encontrados valores médios variando entre 1,71 t/ha, para o híbrido 6, e 2,28 t/ há, para o híbrido 3. As maiores médias de produção de MS/ha foram encontradas no segundo corte, valores intermediários foram encontrados no terceiro corte e inferiores aos demais no primeiro corte.
O valor médio de produção de MS por corte, no presente estudo, foi de 1,99 t/ha, sendo que os valores encontrados estão bem próximos ao valor de 2,29 t/ha encontrado por Carvalho (1996), para dez cultivares de capim Sudão cortadas aos 60 dias pós-plantio. Pereira et al. (1993), estudando a produtividade de gramíneas utilizadas em plantios de sucessão, encontraram produções de MS/ha semelhantes entre um híbrido de sorgo com capim Sudão e o milheto.

Os valores médios de produção total de MS/ha encontrados foram inferiores ao valor médio de 9,5 t/ha, encontrado por Tomich (2003) para doze híbridos de sorgo com capim Sudão, em três cortes consecutivos. Porém, esse autor trabalhou no verão, dificultando as comparações de produção com o presente experimento.

Na Tabela 3, são apresentados os valores referentes à altura das plantas no momento dos cortes.

Observa-se que não houve diferença ( $\mathrm{P}>0,05)$ entre as médias dos híbridos, sendo que os valores variaram de $83,33 \mathrm{~cm}$, para o híbrido 2 (testemunha), a $94,58 \mathrm{~cm}$, para o híbrido 4.

TABELA 2. Produção de matéria seca (MS), expressa em toneladas por hectare (t/ha), dos seis híbridos, nos três cortes realizados

\begin{tabular}{llllll}
\hline Híbridos & Corte $\mathbf{1}$ & Corte $\mathbf{2}$ & Corte $\mathbf{3}$ & Médias & Total \\
\hline 1 & 1,50 & 2,75 & 2,53 & 2,26 & 9,04 \\
2 & 1,53 & 2,04 & 1,93 & 1,83 & 7,33 \\
3 & 1,63 & 2,62 & 2,60 & 2,28 & 9,13 \\
4 & 1,24 & 2,65 & 1,72 & 1,87 & 7,48 \\
5 & 0,90 & 3,30 & 1,67 & 1,96 & 7,83 \\
6 & 0,98 & 2,47 & 1,69 & 1,71 & 6,85 \\
\hline Médias & $1,30 \mathrm{c}$ & $2,64 \mathrm{a}$ & $2,02 \mathrm{~b}$ & 1,99 & \\
\hline
\end{tabular}

Teste SNK ( $\mathrm{p}<0,05), \mathrm{CV}=53,61 \%$. Letras minúsculas comparam médias na mesma linha. Híbridos: 1 = AG2501C; $2=$ BRS800; 3 = ATF54 x 912; $4=$ CMSXS 156 x CMSXS 912; $5=$ CMSXS 157 x CMSXS 912; $6=$ CMSXS 210 x CMSXS 912. 
TABELA 3. Altura média das plantas, expressa em cm, dos seis híbridos, nos três cortes realizados

\begin{tabular}{lllll}
\hline Híbridos & Corte $\mathbf{1}$ & Corte $\mathbf{2}$ & Corte $\mathbf{3}$ & Médias \\
\hline 1 & 97,50 & 86,25 & 86,25 & 90,00 \\
2 & 75,63 & 86,88 & 87,50 & 83,33 \\
3 & 87,50 & 94,38 & 100,00 & 93,96 \\
4 & 87,50 & 102,50 & 93,75 & 94,58 \\
5 & 80,63 & 107,50 & 94,38 & 94,17 \\
6 & 77,50 & 98,75 & 93,00 & 89,75 \\
\hline Médias & 84,38 & 96,04 & 92,48 & 90,97 \\
\hline
\end{tabular}

Teste SNK (p>0,05), CV= 31,30\%. Híbridos: $1=$ AG2501C; $2=$ BRS800; $3=$ ATF54 x 912; $4=$ CMSXS $156 \times$ CMSXS 912; 5 = CMSXS 157 x CMSXS 912; 6 = CMSXS 210 x CMSXS 912.

Não houve diferença $(\mathrm{P}>0,05)$ entre os híbridos dentro do mesmo corte. Comparando-se os cortes, também não houve diferença de altura entre os três cortes sucessivos avaliados.

No presente experimento, houve uma alta correlação entre altura média das plantas e produção de MV/ha e de MS/ha, com valores de 0,82 e $0,77(\mathrm{P}<0,0001)$, respectivamente.

$\mathrm{Na}$ Tabela 4, tem-se o número de plantas por hectare dos híbridos estudados, nos três cortes realizados.

Observando-se as médias de cada híbrido, o número total de plantas variou de 661,91 a 847,87 mil plantas/ha, sendo que o híbrido 3 apresentou população semelhante $(\mathrm{P}>0,05)$ ao híbrido 1 e ao híbrido 2 , e superior $(\mathrm{P}<0,05)$ aos demais híbridos. Ocorreram diferenças entre os híbridos quanto ao número de plantas, sendo que o híbrido 1 foi semelhante aos híbridos 2 e 4 , sendo superior aos demais híbridos. $\mathrm{O}$ híbrido 2 foi semelhante aos híbridos 4 e 5 , sendo superior ao híbrido 6. Diferenças entre os híbridos para número de plantas/há, no primeiro corte, podem indicar uma maior capacidade de germinação e estabelecimento cultural, nas condições experimentais de cultivo, dos híbridos superiores, nesse parâmetro, pois, no presente experimento, foram adotadas medidas para uniformidade de plantio e tratos culturais. Vale ressaltar que não houve, no presente estudo, uma padronização do tamanho das sementes, o que pode também ter influenciado nos resultados obtidos para população inicial de plantas.

Observando-se a média de número de plantas por hectares, verificou-se que a população de plantas diminuiu com o avançar dos cortes, sendo que o primeiro corte foi superior ao segundo e este superior ao terceiro.

Segundo Hold \& Alston (1968), a altura de corte é um fator que pode influenciar a capacidade de perfilhamento de híbridos de sorgo bicolor com capim Sudão, sendo que cortes com menor altura de resíduo promovem um maior grau de perfilhamento devido à maior remoção de meristemas. Entretanto, Soto et al. (1984), trabalhando com um híbrido de sorgo com capim Sudão (Sudax ST-6), não verificaram diferenças na capacidade de perfilhamento entre cortes com altura de resíduo variando de 2,5 a $10 \mathrm{~cm}$. No presente experimento os cortes foram padronizados a cerca de $20 \mathrm{~cm}$ de altura, sendo também adotadas medidas de 
TABELA 4. Número de plantas, expresso em 1000 plantas por hectare (x1000 plantas/ha), dos seis híbridos, nos três cortes realizados

\begin{tabular}{lllll}
\hline Híbridos & Corte 1 & Corte 2 & Corte 3 & Médias \\
\hline 1 & 929 & 853 & 559 & 780AB \\
2 & 946 & 788 & 513 & $749 \mathrm{ABC}$ \\
3 & 1093 & 866 & 585 & $848 \mathrm{~A}$ \\
4 & 824 & 735 & 506 & $688 \mathrm{BCD}$ \\
5 & 826 & 737 & 420 & $661 \mathrm{CD}$ \\
6 & 776 & 682 & 378 & $611 \mathrm{D}$ \\
\hline Médias & $899 \mathrm{a}$ & $777 \mathrm{~b}$ & $493 \mathrm{c}$ & 723 \\
\hline
\end{tabular}

Teste SNK $(p<0,05), C V=21,08 \%$. Letras maiúsculas comparam médias na mesma coluna. Letras minúsculas comparam médias na mesma linha. Híbridos: 1 = AG2501C; 2 = BRS800; 3 = ATF54 x 912; 4 = CMSXS 156 x CMSXS 912; 5 = CMSXS 157 x CMSXS 912; 6 = CMSXS 210 x CMSXS 912.

uniformidade para tratos culturais, o que pode atribuir as diferenças significativas encontradas para a população de plantas entre cortes a características peculiares de cada híbrido, que lhe conferem maior capacidade de adaptação às condições de cultivo e utilização.

A determinação da taxa de rebrota é uma característica importante, pois está relacionada diretamente com o potencial produtivo de forrageiras anuais manejadas em regime de cortes sucessivos. As taxas médias de rebrota de cada híbrido, que podem ser vistas na Tabela 5 , foram obtidas entre o primeiro e o segundo cortes (rebrota 1) e entre o segundo e o terceiro cortes (rebrota 2).

Todos os valores foram inferiores a 1,0, não havendo diferença entre híbridos ( $\mathrm{P}>0,05)$. Comparando-se os valores encontrados nas rebrotas 1 e 2, verifica-se uma tendência de redução do número de plantas/ha após os cortes, porém não houve diferença entre as rebrotas $(\mathrm{P}>0,05)$.

A taxa média de rebrota, entre o primeiro e o segundo cortes, foi inferior a 1,00 , demonstrando a tendência de redução do número de plantas logo após o primeiro corte. Entretanto, Tomich (2003), trabalhando com doze híbridos de capim Sudão com sorgo bicolor, em sistema de cortes sucessivos, relatou uma tendência à redução do número de plantas somente a partir do segundo corte.

O número de cortes realizados, em híbridos de sorgo com capim Sudão, depende não só da época de plantio, mas também dos tratos culturais, das condições ambientais e doobjetivo do cultivo. Segundo Rodrigues (2000), nas condições do Brasil Central, em plantios de verão, considera-se economicamente viável a realização de três cortes, muito embora haja grande influência de fatores edafoclimáticos.

Na Tabela 6, são apresentados os valores da relação folha/haste observados neste experimento.

Nota-se que não houve diferença $(\mathrm{P}>0,05)$ entre as médias dos híbridos, sendo que os valores variaram de 0,69 a 0,90.

Comparando-se os cortes, os híbridos tiveram valores superiores no corte 1 , sendo os cortes 2 e 3 semelhantes para todos os híbridos. 
TABELA 5. Taxas de rebrota dos seis híbridos, nos três cortes realizados

\begin{tabular}{llll}
\hline Híbridos & Rebrota 1 & Rebrota 2 & Médias \\
\hline 1 & 0,91 & 0,67 & 0,79 \\
2 & 0,79 & 0,74 & 0,76 \\
3 & 0,79 & 0,71 & 0,75 \\
4 & 0,84 & 0,75 & 0,79 \\
5 & 0,70 & 0,79 & 0,75 \\
6 & 0,74 & 0,69 & 0,72 \\
\hline Médias & 0,80 & 0,72 & 0,76 \\
\hline
\end{tabular}

Teste SNK (p>0,05), CV= 30,49\%. Híbridos: $1=$ AG2501C; $2=$ BRS800; $3=$ ATF54 x 912; $4=$ CMSXS 156 x CMSXS 912; 5 = CMSXS 157 x CMSXS 912; 6 = CMSXS 210 x CMSXS 912.

A relação folha/haste é uma característica importante na previsão do valor nutritivo da forrageira. Ela indica a participação relativa de folhas na forragem total. Essa alta proporção constitui uma característica desejável para as plantas forrageiras, por estar diretamente associada à qualidade e ao consumo (Tomich et al., 2004).

Conceitos mais modernos de programas de melhoramento objetivam explorar o máximo possível o banco genético da cultura de sorgo, buscando selecionar materiais com qualidade de colmo e folhas, visando aumentar o valor nutritivo da planta (Neumann et al., 2002a), sendo a relação entre essas frações de grande importância no valor nutritivo do alimento.

Observou-se correlação negativa de $-0,60$ $(\mathrm{P}<0,0001)$ entre altura das plantas e a relação folha/haste. Correlações semelhantes foram descritas por Tomich (2003), que encontrou correlação positiva da altura das plantas com os parâmetros de produção e negativa com a relação folha/haste, para doze híbridos de sorgo com capim Sudão.

TABELA 6. Relação folha/haste dos seis híbridos, nos três cortes realizados

\begin{tabular}{lllll}
\hline Híbridos & Corte $\mathbf{1}$ & Corte $\mathbf{2}$ & Corte $\mathbf{3}$ & Médias \\
\hline 1 & 0,99 & 0,83 & 0,57 & 0,80 \\
2 & 1,08 & 0,61 & 0,55 & 0,75 \\
3 & 1,19 & 0,59 & 0,46 & 0,75 \\
4 & 1,04 & 0,56 & 0,48 & 0,69 \\
5 & 1,40 & 0,64 & 0,56 & 0,87 \\
6 & 1,36 & 0,76 & 0,57 & 0,90 \\
\hline Médias & $1,18 \mathrm{a}$ & $0,66 \mathrm{~b}$ & $0,53 \mathrm{~b}$ & 0,79 \\
\hline
\end{tabular}

Teste SNK $(\mathrm{p}<0,05), \mathrm{CV}=50,43 \%$. Letras minúsculas comparam médias na mesma linha. Híbridos: $1=$ AG2501C; 2 = BRS800; 3 = ATF54 x 912; 4 = CMSXS 156 x CMSXS 912; 5 = CMSXS 157 x CMSXS 912; $6=$ CMSXS 210 x CMSXS 912. 


\section{Conclusões}

As produtividades médias de 15,32T/ha de MV e 1,99T/ha de MS indicam o potencial dos híbridos de sorgo com capim Sudão estudados, para serem utilizados como alternativa para a produção de forragem em regime de corte, na transição do período seco para o período chuvoso, no Brasil Central.

Os híbridos estudados não diferiram para a maioria das características avaliadas, com exceção da população de plantas, em que o híbrido experimental ATF $54 \mathrm{x}$ CMSXS 912, com 848 mil plantas/ha, foi semelhante $(\mathrm{P}>0,05)$ aos híbridos testemunhas (comerciais) AG2501C, com 780 mil plantas/ ha, e ao BRS800, com 749 mil plantas/ha, sendo superior $(\mathrm{P}<0,05)$ aos demais híbridos.

\section{Literatura Citada}

AGUIAR, E. M.; LIMA, G. F. C.; SANTOS, M. V. F.; CARVALHO, F. F. R.; GUIM, A.; MEDEIROS, H. R.; BORGES, A. Q. Rendimento e composição químicobromatológica de fenos triturados de gramíneas tropicais. Revista Brasileira de Zootecnia, Viçosa, v. 35, n. 6. p. 2226-2233, 2006.

BEYAERT, R. P.; ROY, R. C. Influence of nitrogen fertilization on multi-cut forage sorghum-sudangrass yield and nitrogen use. Agronomy Journal, Madison, v. 97, p. 14931501, 2005.

CARVALHO, L. C. Determinação do valor nutritivo de dez cultivares de capim sudão (Sorghum sudanense). 1996. 100 f. Dissertação (Mestrado) - Escola de Veterinária, Universidade Federal de Minas Gerais, Belo
Horizonte.

CUNIFF, P. (Ed.). Official methods of analysis of AOAC International. 16. ed. Gaithersburg: AOAC International, 1995. 2000 p. Mudar no texto Association para Cuniff.

GONTIJO NETO, M. M.; OBEID, J. A.; PEREIRA, O. G.; CECON, P. R.; CÂNDIDO, M. J. D.; MIRANDA, L. F. Híbridos de sorgo (Sorghum bicolor (L.) Moench) cultivados sob níveis crescentes de adubação. rendimento, proteína bruta e digestibilidade in vitro. Revista Brasileira de Zootecnia, Viçosa, v. 31, n. 4, p. 1640-1647, 2002

HOLD, C. E.; ALSTON, G. D. Response of sudangrass hybrids to cutting pratices. Agronomy Journal, Madison, v. 60, n. 3, p. 303-306, 1968.

NEUMANN, M.; RESTLE, J.; ALVES FILHO, D. C.; BERNARDES, R. A. C.; ARBOITE, M. Z.; CERDÓTES, L.; PEIXOTO, L. A. O. Avaliação de diferentes híbridos de sorgo (Sorghum bicolor, 1. Moench) quanto aos componentes da planta e silagens produzidas. Revista Brasileira de Zootecnia, Viçosa, v. 31, n. 1, p. 302-312, 2002a Suplemento.

NEUMANN, M.; RESTLE, J.; ALVES FILHO, D. C.; BRONDANI, I. L.; PELLEGRINI, L. G.; FREITAS, A. K. Avaliação do valor nutritivo da planta e da silagem de diferentes híbridos de sorgo (Sorghum bicolor, L. Moench). . Revista Brasileira de Zootecnia, Viçosa, v. 31, n.1, p. 293-301, 2002b Suplemento.

PEREIRA, O. G.; OBEID, J. A.; GOMIDE, J. A. Produtividade e valor nutritivo de 
aveia (Avena sativa), milheto (Pennisetum americanum L.), e de um híbrido de Sorghum bicolor $x$ S. sudanense. Revista Brasileira de Zootecnia, Viçosa, v. 22, n. 1, p. 22-31, 1993.

RODRIGUES, J. A. S. Utilização de forragem fresca de sorgo (Sorghum bicolor x Sorghum sudanense) sob condições de corte e pastejo. In: SIMPÓSIO DE FORRAGICULTURA E PASTAGENS, 1., 2000. Lavras. Temas em evidência. Lavras: UFLA, 2000. p.179-201. Editado por Antonio Ricardo Evangelista, Thiago Fernandes Bernardes, Eleuza Clarete Junqueira de Sales.

RODRIGUES, P. H. M.; SENATORE, A. N.; ANDRADE, S. J. T.; RUZANTE, J. M.; LUCCI, C. S.; LIMA, F. R. Efeitos da adição de inoculantes microbianos sobre a composição bromatológica e perfil fermentativo da silagem de sorgo produzida em silos experimentais. Revista Brasileira de Zootecnia, Viçosa, v. 31, n. 6, p. 2373-2379, 2002.

SOTO, P. O.; FIGUEROA, M.; MARTINEZ, C. R. Frecuencia e intensidade de utilización de un hibrido de sorgo x pasto sudan en suelos arroceros. Agricultura Tecnica, Santiago, v. 44, n. 3, p. 237-243, 1984.

TOMICH, T. R.; TOMICH, R. G. P.; GONÇALVES, L. C.; BORGES, I.; RODRIGUES, J. A. S.. Valor nutricional de híbridos de sorgo com capim-sudão em comparação ao de outros volumosos utilizados no período de baixa disponibilidade das pastagens. Arquivo Brasileiro de Medicina Veterinaria e Zootecnia, Belo Horizonte, v. 58, n. 6, p.1249-1252, 2006.

TOMICH, T. R.; RODRIGUES, J. A. S.; TOMICH, R. G. P.; GONÇALVES, L. C.; BORGES, I. Potencial forrageiro de híbridos de sorgo com capim sudão. Arquivo Brasileiro de Medicina Veterinaria e Zootecnia, Belo Horizonte, v. 56, n. 2, p. 258-263, 2004.

TOMICH, T. R.; GONÇALVES, L. C.; MAURÍCIO R. M.; PEREIRA L. G. R.; RODRIGUES J. A.S. Composiçãobromatológica e cinética de fermentação ruminal de híbridos de sorgo com capim sudão. Arquivo Brasileiro de Medicina Veterinaria e Zootecnia, Belo Horizonte, v. 55, n. 6, p.747-755, 2003.

TOMICH, T.R. Potencial forrageiro de híbridos de sorgo com capim Sudão (Sorghum bicolor $x$ Sorghum sudanense) avaliados em regime de corte. 2003. $88 \mathrm{f}$. Tese (Doutorado) - Escola de Veterinária, Universidade Federal de Minas Gerais, Belo Horizonte.

UNIVERSIDADE FEDERAL DE VIÇOSA. SAEG - Sistema de análises estatísticas e genéticas (manual do usuário). Versão 8.0. Viçosa: MG, 2000.142 p.

WHEELER, J. L. Increasing animal production from sorghum forage. World Animal Review, Rome, n. 35, p. 13-22, 1980.

ZAGO, C. P. Utilização de sorgo na alimentação de ruminantes. In: EMBRAPA Centro Nacional de Pesquisa de Milho e Sorgo. Manejo cultural do sorgo para forragem. Sete Lagoas, 1997. p. 9-26. (EMBRAPACNPMS. Circular Técnica, 17). 